\title{
Immunomodulating Profile of Dental Mesenchymal Stromal Cells: A Comprehensive Overview
}

\author{
Alessia Paganelli ${ }^{1,2}$, Oriana Trubiani ${ }^{3 \dagger}$, Francesca Diomede ${ }^{3}$, Alessandra Pisciotta ${ }^{2}$ and \\ Roberto Paganelli ${ }^{4,5 * t}$
}

${ }^{1}$ PhD Program in Clinical and Experimental Medicine, University of Modena and Reggio Emilia, Modena, Italy, ${ }^{2}$ Surgical, Medical and Dental Department of Morphological Sciences Related to Transplant, Oncology and Regenerative Medicine, University of Modena and Reggio Emilia, Modena, Italy, ${ }^{3}$ Department of Medical, Oral and Biotechnological Sciences, University "G. D'Annunzio" Chieti-Pescara, Chieti, Italy, ${ }^{4}$ Department of Medicine and Aging Sciences, University "G. D'Annunzio" Chieti-Pescara, Chieti, Italy, ${ }^{5}$ YDA, Institute of Clinical Immunotherapy and Advanced Biological Treatments, Pescara, Italy

\section{OPEN ACCESS}

Edited by: Oleh Andrukhov

University Dental Clinic Vienna, Austria

Reviewed by: Constanza Eugenia Martinez, Pontificia Universidad Católica de Chile, Chile

Christian Behm

University Dental Clinic Vienna, Austria

*Correspondence:

Roberto Paganell roberto.paganelli@unich.it

${ }^{\dagger}$ Present address: Oriana Trubiani and Roberto Paganelli, StemTeCh Group, Chieti, Italy

Specialty section: This article was submitted to Oral Infections and Microbes, a section of the journal Frontiers in Oral Health

Received: 29 November 2020 Accepted: 23 February 2021 Published: 31 March 2021

Citation:

Paganelli A, Trubiani O, Diomede F, Pisciotta A and Paganelli R (2021) Immunomodulating Profile of Dental

Mesenchymal Stromal Cells: $A$ Comprehensive Overview.

Front. Oral. Health 2:635055 doi: 10.3389/froh.2021.635055
Dental mesenchymal stromal cells (MSCs) are multipotent cells present in dental tissues, characterized by plastic adherence in culture and specific surface markers (CD105, CD73, CD90, STRO-1, CD106, and CD146), common to all other MSC subtypes. Dental pulp, periodontal ligament, apical papilla, human exfoliated deciduous teeth, alveolar bone, dental follicle, tooth germ, and gingiva are all different sources for isolation and expansion of MSCs. Dental MSCs have regenerative and immunomodulatory properties; they are scarcely immunogenic but actively modulate $T$ cell reactivity. in vitro studies and animal models of autoimmune diseases have provided evidence for the suppressive effects of dental MSCs on peripheral blood mononuclear cell proliferation, clearance of apoptotic cells, and promotion of a shift in the Treg/Th17 cell ratio. Appropriately stimulated MSCs produce anti-inflammatory mediators, such as transforming growth factor- $\beta$ (TGF- $\beta$ ), prostaglandin E2, and interleukin (IL)-10. A particular mechanism through which MSCs exert their immunomodulatory action is via the production of extracellular vesicles containing such anti-inflammatory mediators. Recent studies demonstrated MSC-mediated inhibitory effects both on monocytes and activated macrophages, promoting their polarization to an anti-inflammatory M2-phenotype. A growing number of trials focusing on MSCs to treat autoimmune and inflammatory conditions are ongoing, but very few use dental tissue as a cellular source. Recent results suggest that dental MSCs are a promising therapeutic tool for immune-mediated disorders. However, the exact mechanisms responsible for dental MSC-mediated immunosuppression remain to be clarified, and impairment of dental MSCs immunosuppressive function in inflammatory conditions and aging must be assessed before considering autologous MSCs or their secreted vesicles for therapeutic purposes.

Keywords: T cells, immunomodulation, dental, cytokines, extracellular vesicles, mesenchymal stem cells (MeSH ID D059630) 


\section{INTRODUCTION}

Mesenchymal stromal cells (MSCs) are a subset of multipotent cells present in tissues of mesenchymal origin, mainly responsible for their regeneration. MSCs were first identified as a specific subset of spindle-shaped cells in the bone marrow, characterized by adherence to plastic under standard culture conditions, with the potential for clonogenic proliferation. In 2006, the Mesenchymal and Tissue Stem Cell Committee of the International Society for Cellular Therapy defined three minimal criteria for MSCs: plastic adherence, ability to differentiate into chondroblasts, osteoblasts, and adipocytes in vitro, and the presence of several specific surface markers, such as CD105, CD73, and CD90 [1]. More recently, the nomenclature has been revised, and novel specific surface molecules have been identified: MSCs are now defined also as STRO-1, CD106, and CD146 positive cells [2-5].

After the isolation and characterization of bone marrow stromal stem cells (BMSCs), other MSC-like populations have been identified in other tissues and organs $[6,7]$. MSC sources include umbilical-cord, amniotic-fluid, adipose, and dental tissue [8-10]. Similar MSC populations can also be found in skeletal muscle, synovium, liver, lungs, tendons, placenta, dermis, and breast milk [11-15].

All MSC subpopulations not only share selfrenewal capabilities and multipotency but also display immunomodulatory properties $[16,17]$.

With regard to dental tissue-derived MSCs, eight different subsets of MSCs have been identified so far: dental-pulp MSCs (DPMSCs), periodontal-ligament MSCs (PDLMSCs), MSCs from apical papilla (MSCAPs), MSCs from human exfoliated deciduous teeth (MSCHEDTs), alveolar bone-derived MSCs (ABMSCs), dental follicle progenitor cells (DFPCs), tooth germ progenitor cells (TGPCs), and gingival MSCs (GMSCs) [18-20]. MSCs derived from the oral cavity are particularly interesting in terms of their embryogenesis in that dental MSCs originate from migrating neural crest cells in the lateral ridges of the neural plate [21]. Neural crest cells possess stemness and multipotency features, play a strategic role in tooth organ development, and contribute to craniofacial bone formation [22].

As for other types of MSCs, dental MSCs are currently widely studied for their immune properties [23]. Here, we briefly describe the immunomodulating properties typical for each subset of MSCs (see Figure 1).

\section{DENTAL PULP MESENCHYMAL STROMAL CELLS}

DPMSCs were the first human dental MSCs identified in 2000 by Gronthos et al. [24]. DPMSCs are today widely used in clinical trials for regenerative purposes. Many groups already demonstrated that DPMSCs are capable of $\mathrm{T}$ cell inhibition and therefore have the potential for modulating $\mathrm{T}$ cell reactivity associated with both autoimmune diseases and allogeneic tissue transplantation [25]. Inhibition of peripheral blood mononuclear cell proliferation in vitro is thought to occur via the production of soluble factors secreted by DPMSCs, induced by interferon (IFN) $-\gamma$. The immunosuppressive effect of DPMSCs was alternatively shown to be triggered by activation of Toll-like receptors (TLRs) through the upregulation of specific cytokines and growth factors, such as IL-6 and TGF- $\beta$ [26]. In addition, DPMSCs can induce apoptosis of activated $\mathrm{T}$ cells via direct cell-to-cell interactions, mediated by the Fas ligand [27]. DPMSCs also interact with activated neutrophils: a recent article demonstrated enhanced IFN- $\gamma$ and IL- 6 production after coculturing. Moreover, rapid and significant commitment toward the osteogenic lineage is achieved by neutrophilexposed DPMSCs [28]. DPMSCs' immunomodulatory ability was deeply investigated by Martinez and co-authors in in vitro-induced hypoxic conditions. DPMSCs were not only shown to dampen dendritic cell (DC) differentiation from monocytes but also efficiently recruited monocytes with immunosuppressive potential, as demonstrated by the M2phenotype of macrophages and high levels of IL-10. Moreover, DPMSCs were demonstrated both to determine impairment in natural killer (NK) degranulation and to have enhanced resistance to NK cell-mediated lysis. Lastly, DPMSCs' proangiogenic properties were also described [29]. Several authors have hypothesized the presence of different subpopulations with different activity among DPMSCs [30]; whether the immunosuppressive phenotype strictly correlates with the presence of specific surface markers still needs to be determined.

\section{MESENCHYMAL STROMAL CELLS FROM HUMAN EXFOLIATED DECIDUOUS TEETH}

MSCHEDTs are the DPMSC's counterpart in deciduous teeth, discovered in 2003 by Miura et al. [31]. MSCHEDTs significantly inhibit the differentiation of the pro-inflammatory subset of $\mathrm{T}$ helper 17 (Th17) cells and promote the induction of regulatory $\mathrm{T}$ cells (Tregs) ex vivo, being even more efficient than BMSCs for Th17 inhibition [32]. Their immunomodulatory effect has already been demonstrated in canine models of muscular dystrophy [33].

In murine models, systemic infusion of MSCHEDTs was able to effectively reverse systemic lupus erythematosus (SLE)associated manifestations, probably because of a shift in the Treg/Th17 cell ratio. Potentially, their efficacy in SLE models could also be due to clearance of apoptotic cells by MSCHEDTs, as already demonstrated for other types of MSCs [34].

\section{PERIODONTAL LIGAMENT MESENCHYMAL STROMAL CELLS}

PDLMSCs were isolated and described in detail for the first time by Seo et al. [35] and Trubiani et al. [36]. PDLMSCs, similar to other MSCs of different origins, are sensitive to specific stimuli. One such stimulus for the expression of immunomodulatory properties is a coculture with peripheral blood mononuclear cells and specific cytokines such as IFN- $\gamma[37,38]$. After in vitro exposure to IFN- $\gamma$, the expression of hepatocyte growth factor, indoleamine 2,3-dioxygenase (IDO), and TGF- $\beta$ was 

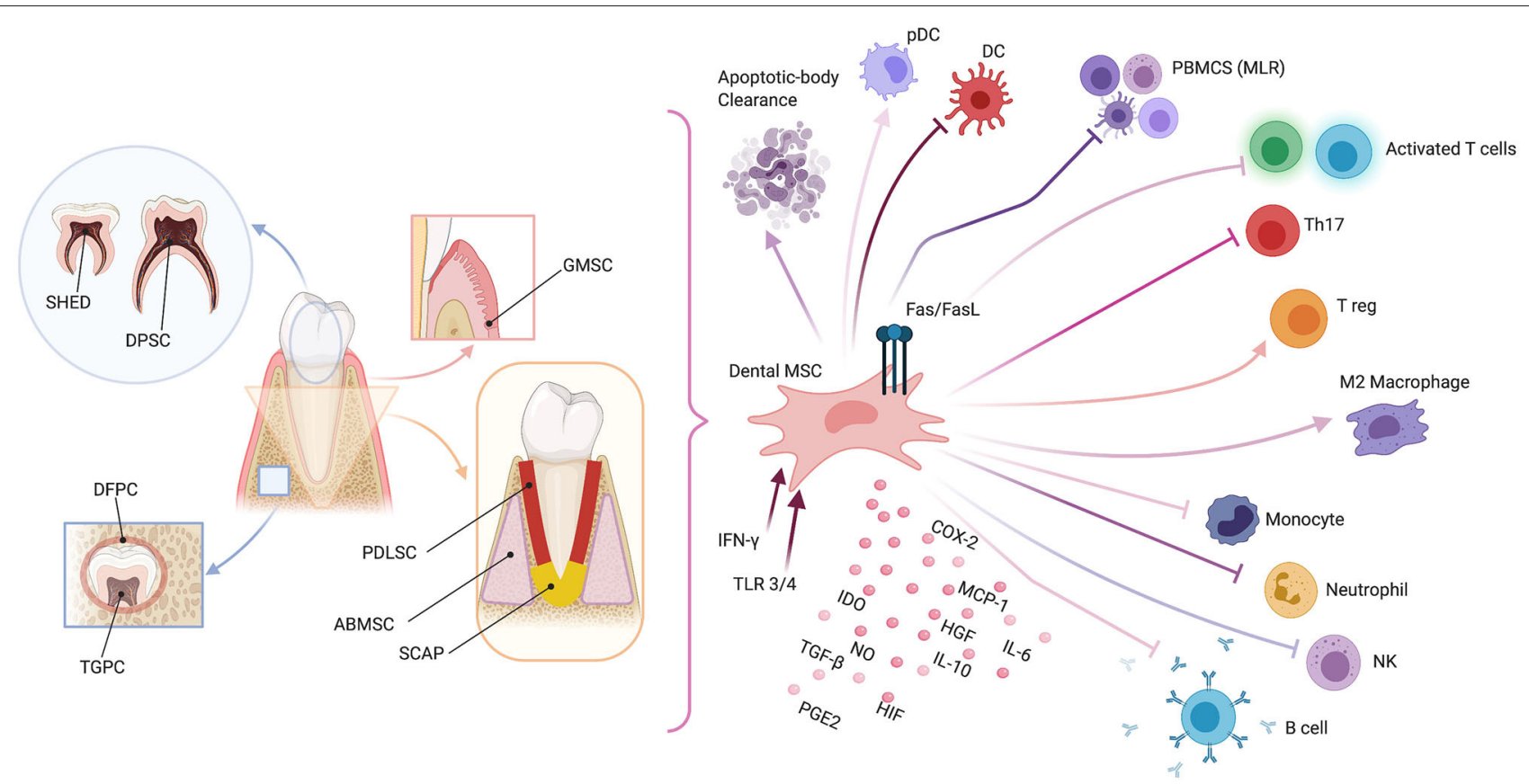

FIGURE 1 | Schematic representation of dental mesenchymal stromal cell (MSC) sources (left panel) and possible immunomodulating mechanisms (right panel). Dental pulp MSCs (DPMSCs), MSCs from human exfoliated deciduous teeth (MSCHEDTs), periodontal ligament MSCs (PDLMSCs), alveolar-bone derived MSCs (ABMSCs), gingival MSCs (GMSCs), MSCs from apical papilla (MSCAPs), dental follicle progenitor cells (DFPCs), and tooth germ progenitor cells (TGPCs). Peripheral blood mononucleated cells (PBMCS), mixed lymphocyte reaction (MLR), plasmacytoid dendritic cell (pDC), natural killer (NK), type-2 cyclooxygenase (COX2), Fas ligand (FasL), indoleamine 2,3-dioxygenase (IDO), nitric oxide (NO), transforming growth factor- $\beta$ (TGF- $\beta$ ), hepatocyte growth factor (HGF), prostaglandin E2 (PGE2), hypoxia-induced factor (HIF), interleukins 6 and 10 (IL6 and IL10, respectively), monocyte chemoattractant protein-1 (MCP-1), Toll-like receptor (TLR), and interferon- $\gamma$ $(\mathrm{FN}-\gamma)$. Created with BioRender.com.

upregulated, leading to immunosuppression [39]. PDLMSCs were also shown to induce $\mathrm{T}$ cell anergy through the secretion of prostaglandin E2 (PGE2) [40].

In animal models of experimental autoimmune encephalomyelitis, decreased signs of inflammation and demyelination in the spinal cord are observed after injection of PDLMSCs, both through the increased production of neurotrophic factors and the suppression of inflammatory mediators [41]. The cell-conditioned medium reduced inflammatory damage in the same model and purified extracellular vesicles from PDLMSCs that mediated similar effects [42]. The vesicles were found to contain the antiinflammatory cytokines IL-10 and TGF- $\beta$. However, PDLMSCs from inflamed periodontium were shown recently to have significantly diminished inhibitory effects on $\mathrm{T}$ cell proliferation, compared with cells from healthy tissue, mainly due to a reduced induction of Tregs [43]. These findings may be relevant to the pathogenesis of periodontitis and should direct the efforts toward developing therapeutics for periodontitis by exploiting immunomodulation.

\section{MESENCHYMAL STROMAL CELLS OF APICAL PAPILLA}

The apical papilla is the part of the soft tissue found at the apex of developing teeth. MSCAPs were discovered in human immature permanent teeth in 2006 by Sonoyama et al. [44, 45].
Relative to DPMSCs, MSCAPs show higher proliferation rates and mediate more efficient regeneration of the dentin matrix. Thus, developing dental tissues are probably a better source of immature stromal cells. MSCAPs are scarcely immunogenic and inhibit mixed lymphocyte reactions mainly through the secretion of soluble factors [46]. Conveniently, cryopreservation does not seem to alter MSCAPs' immune properties [47].

\section{ALVEOLAR BONE MESENCHYMAL STROMAL CELLS}

Recently, a unique population of MSCs referred to as ABMSCs has been isolated from the alveolar bone [48]. The isolation procedure is considered particularly easy and feasible when performed during implant positioning. These cells morphologically and functionally resemble the other types of dental MSCs described. Very recent studies confirmed in vitro ABMSCs' immunosuppressive effects both on monocyte and $\mathrm{T}$ cell activation. Moreover, ABMS was found to induce polarization of macrophages toward an anti-inflammatory phenotype (M2) and was able to secrete IL-6 and MCP-1 [49].

\section{DENTAL FOLLICLE PRECURSOR CELLS}

The dental follicle (DF) is a vascular fibrous sac containing the developing tooth and its odontogenic organ before eruption [50]. 
The DF eventually differentiates into the periodontal ligament. A subset of progenitor cells with the characteristics of MSCs was isolated from the DF of human third molars in 2005 by Morsczeck et al. using the same protocol as Gronthos et al. used before for DPMSCs [51]. Recent studies have shown that DFPCs can inhibit the mixed lymphocyte reactions and elicit macrophage M2 polarization, mainly through TGF- $\beta$ production [52]. Moreover, treatment with TLR3 and TLR4 agonists potentiates TGF- $\beta$ and IL-6 secretion [53]. These characteristics make DFPCs promising candidates for the treatment of chronic inflammatory conditions.

\section{TOOTH GERM PROGENITOR CELLS}

TGPCs were identified by Ikeda et al. in the dental mesenchyme of the third molar tooth germ during the late bell stage. TGPCs have been successfully transplanted in rat models of chronic hepatitis, preventing the progression of liver fibrosis and contributing to the normalization of liver function [54]. Thus far, little is known about TGPCs' immunomodulatory mechanisms.

\section{GINGIVA-DERIVED MESENCHYMAL STROMAL CELLS}

Zhang et al. [55] identified human gingiva-derived MSCs in 2009. GMSCs are easily isolated and rapidly expanded ex vivo, thus potentially representing an optimal source of MSCs in the clinical setting. GMSCs have been shown to efficiently inhibit $\mathrm{T}$ cell proliferation in response to mitogen stimulation and to induce IDO, IL-10, cyclooxygenase 2 , and inducible nitric oxide synthase through IFN- $\gamma$ secretion, thereby exerting a wide-ranging antiinflammatory and immunomodulating action [56].

In animal models of contact hyper-reactivity and in an autoimmune arthritis model, systemic infusion of GMSCs attenuated pathological damage and suppressed Th17 activity, with a significant increase both in Tregs differentiation and IL10 production [57]. Moreover, GMSCs elicited M2 polarization of macrophages and decreased Th17 cell expansion [58]. In addition, murine models of chemotherapy-induced oral mucositis showed significant clinical improvement after GMSC administration: in this setting, increased levels of manganese superoxide dismutase and hypoxia-inducible factors 1 and $2 \alpha$ were associated with lower rates of oxidative stress-induced apoptosis of epithelial cells [29].

\section{ADDITIONAL DATA ON DENTAL MESENCHYMAL STROMAL CELLS AND OTHER CELL SOURCES}

Our paper focused on MSC interaction mainly with $\mathrm{T}$ cells and macrophages because most of the existing data on dental MSCs are restricted to these cell subtypes. However, MSCs in general have been deeply investigated for their interactions with other immune cells, with the majority of data coming from bone marrow MSCs [59].
MSCs notably inhibit the maturation of DCs and can promote plasmacytoid DC differentiation, with subsequent Th2 polarization of the immune response [60,61]. Both PGE2 and IL-6 secretions have been postulated as possible mechanisms for DC modulation by MSCs $[62,63]$. NK cells also interact with MSCs and are sometimes responsible for their death through cell lysis [64]. However, although only partially interfering with activated-NK activity, MSCs can block the proliferation of resting NKs. Moreover, MSCs prevent DC-mediated induction of T-cell effector functions, IDO and PGE2 being key mediators in this setting [65]. MSCs are also capable of B cell inhibition and can block antibody production [66]. Programmed-death-1 pathway, CCL2 production, and Blimp-1 inhibition seem to be responsible for this action [67, 68]. Finally, MSCs are demonstrated to promote the proliferation of CD4+ CD25+ FOXP3 + Tregs both in vitro and in vivo [69-71].

Although those data have not entirely been confirmed for dental MSCs, it is possible to hypothesize similar mechanisms underlying their immunomodulatory action. In fact, several comparative studies between dental MSCs and MSCs from other sources have been performed in the last years, but although significant differences were found in proliferative potential and both regenerative and differentiating properties, none of them was focused on immune-modulatory capabilities $[72,73]$.

\section{DISCUSSION}

MSCs have already been used as cell-based immunosuppressive therapies for various disorders, including neurologic, ocular, oral, cutaneous, cardiovascular, and autoimmune diseases $[74,75]$. A growing number of clinical trials are using MSCs for therapeutic interventions in severe degenerative and inflammatory disorders. At the time of writing, almost more than 1,000 clinical trials were registered worldwide at ClinicalTrials.gov [4, 76], with MSCs becoming a powerful new tool for effective immunosuppression avoiding many unwanted adverse effects of conventional drugs [77]. Some types of dental MSCs have been shown to share both regenerative and immunoregulatory potentials, which are becoming extremely relevant for tissue engineering and regenerative medicine [78]. However, very few studies have explored their interactions with immune cells in any depth, and much less is known about the possible mechanisms of their activity. Taking into account the different types of MSCs isolated from teeth, including DPMSCs, MSCHEDTs, GMSCs, PDLMSCs, ABMSCs, DFPCs, and TGPCs, representing an easily accessible source of multipotent cells for clinical applications $[79,80]$, we are still far from a systematic investigation and comparative appreciation of their immunomodulatory properties [81].

One difficulty in such studies resides in the complexity of the stroma, whose tissue-resident cells interact in many ways with immune cells. The characterization of stromal subsets, which are often identified by combinations of markers that are not cell type-specific, has not been extensively carried out [82]. These subsets of mature stromal cells and MSCs from 
different tissues (bone marrow, adipose tissue, and umbilical cord, better studied so far) both promote active responses and suppress immune effector cells through regulatory circuits. Tissue stromal cells under inflammatory conditions drive the formation of immune cell aggregates, termed tertiary lymphoid structures [83], which disappear on a resolution of inflammation [84]. These structures actively drive inflammation, autoimmune responses, and autoantibody production, as well as promoting cancer progression, as prominently described in the lymph node stroma [85], but they also harbor tolerogenic potential, which depends on the inflammatory environment to be licensed [86].

Several mechanisms and molecules have been proposed for the immunoregulatory activity of MSCs in general, involving both cell contact and soluble mediators [87]. These have a protective role and stimulate growth and survival through paracrine secretion of bioactive molecules, collectively defined as the secretome. In many instances, the secretome has been shown to account for the effects of MSCs, so its exploitation may avoid the limitations associated with stem cell therapy $[88,89]$. The secretome also contains extracellular vesicles (EVs) [90]. These released membrane vesicles, including exosomes, microparticles, microvesicles, and apoptotic bodies, can be regarded as a dynamic extracellular vesicular compartment, strategic for their paracrine or autocrine biological effects. They can contribute to tissue regeneration, but with their content rich in cytokines, chemokines, enzymes, growth factors, microRNAs, and other molecules, they may also be responsible for controlling interactions with immune cells, ensuring prevention of excessive tissue fibrosis, stimulation of angiogenesis, and immunomodulatory effects [91]. However, as for different sources of MSCs, and different culture and passage conditions, also for the secretome, differences in production protocols, cell source, and cellular age all impact its composition and anti-inflammatory action [92]. There is a need for focused mechanistic studies and standardized functional assays in the area of immunomodulation by MSCs because they are usually assessed by in vitro tests of inhibition of $\mathrm{T}$ lymphocyte proliferation, and only a few studies compare MSCs from different tissue sources, none at present with dental MSCs [93]. There is general agreement that pro-inflammatory environments are not permissive for endogenous stem and progenitor cells to initiate regenerative processes because stem and progenitor cells require a tolerogenic niche to survive and to promote repair and regeneration. MSCs from teeth have a central role in dampening inflammation locally as in periodontitis [94], and they achieve this effect through their secretome [93] and EVs. The cytokine content and immunoregulatory effect effects of the latter are variable across different diseases, so that the MSCs-EV fraction should be carefully evaluated in the context of the condition studied for the best therapeutic potential.

Although there are no direct studies of MSC interactions with neutrophils in tissues, MSCs inhibit neutrophil apoptosis, although they have no inhibitory effect on their phagocytic and chemotactic activity [95]. MSCs generally reduce the activation of innate immunity [92], and many of their effects are due to the secretion of IL-6, PGE2, and IL-17. Stromal cells also play a role in the induction of myeloid-derived suppressor cells, which can be a pathological differentiated type of neutrophil, in several conditions, including cancer, sepsis, and viral infections [96]. MSCs and their EVs have been shown to induce conversion of pro-inflammatory M1 into M2 macrophages, and EVs released by M2 macrophages can subsequently promote Treg formation [97-99]. MSCs also modulate immune cell function through inhibition of dendritic cell maturation and suppress the functions of T lymphocytes, B lymphocytes, and NK cells. Many reviews have appeared on this issue of immunosuppression related to clinical uses, for example [100-102].

Pulp-derived MSCs have been proposed for treating systemic disorders [87] and other types of MSCs, particularly in the area of neuroinflammatory and neurodegenerative diseases [103, 104], whereas EVs have been advocated for the control and therapy of autoimmunity [105]. This promising outlook is certainly reinforced by progress in transcriptomics and single-cell analysis of MSCs [106, 107], revealing different subsets and mechanisms of action. It is therefore not surprising that MSCs or their exosomes have recently been suggested as a treatment for severe COVID-19 [108-111]. This potential therapeutic strategy has been successfully used in a few reported cases [112] and is mainly based on the known immunomodulating actions of MSCs in acute respiratory infections, through induction of Tregs [113] and in their ability to counteract proinflammatory cytokines [114].

Recent studies have highlighted that MSCs aging may limit their function and therapeutic potential, with some evidence for reducing their immunosuppressive activity [115-117]. Senescent MSCs show decreased proliferative activity, smaller MSCs$\mathrm{EV}$ size, and lower production of cytokines and chemokines; their ability to inhibit $\mathrm{T}$ cell proliferation is impaired while not suppressing NK, B lymphocytes, and macrophages [76, 118]. To address this issue, changes in the expression profiles (including transcriptomic, proteomic, epigenetic, and noncoding RNAs) of senescent MSCs have been explored, and some rejuvenation strategies devised, starting from the modulation of the microenvironment under hypoxic conditions [119, 120]. Data mining several genetic datasets, coupled with powerful bioinformatics applications, have revealed that upregulation of HLA class II antigen expression is central to the changes of aged MSCs, causing a pro-inflammatory phenotype and a decreased immunosuppressive function [121]. Again, little is known about replicative senescence (and its markers) and other effects of aging on dental MSCs.

The immunomodulatory properties of MSCs, at variance with other stem cells, contribute greatly to their therapeutic effects not only in immune-mediated diseases but also for the repair of tissue damages. This has been chiefly verified in several neurodegenerative disorders, such as Alzheimer's disease, amyotrophic lateral sclerosis, and Parkinson's disease, as well as in cerebrovascular damage and autoimmune disease as multiple sclerosis. The glia cells, activated in these conditions, constitute the main targets of the immunosuppressive action of MSCs [103]. Other cell types, predominantly macrophages, but also dendritic cells, induce a different inflammatory environment, in response to which MSCs display regulatory mechanisms 
tailored to the local situation and, thus, have been used for the treatment of various conditions such as graft-vs.-host disease [122], systemic lupus erythematosus [123], liver cirrhosis [124], and inflammatory bowel disease [125]. Their potential use in treating fibrotic and inflammatory diseases such as systemic sclerosis, chronic obstructive pulmonary disease, pulmonary fibrosis, and also severe asthma and COVID-19 should now be the logical next step forward.

These immunoregulatory properties and long-term stability of dental MSCs are of paramount importance for developing their application to autoimmune and other inflammatory conditions, as well as for continued renewal in regenerative medicine, as dampening inflammatory reactions promotes proliferation and differentiation of MSCs. Present data suggest that dental MSCs may be a useful source of MSCs for treating immunemediated diseases.

However, the exact mechanisms responsible for dental MSCmediated immunosuppression remain to be clarified. Moreover, it is not known whether dental MSCs' immunosuppressive function is impaired under local as well as systemic inflammatory conditions. This point is crucial to understanding whether autologous PDLC could be a reasonable source of MSCs for the treatment of autoimmune and other disorders. Despite the promising results achieved in dental MSCs and immunomodulation, this area of research needs to be methodically investigated.

\section{REFERENCES}

1. Dominici M, Le Blanc K, Mueller I, Slaper-Cortenbach I, Marini F, Krause $\mathrm{D}$, et al. Minimal criteria for defining multipotent mesenchymal stromal cells. The International Society for Cellular Therapy position statement. Cytotherapy. (2006) 8:315-7. doi: 10.1080/14653240600855905

2. Han ZC, Du WJ, Han ZB, Liang L. New insights into the heterogeneity and functional diversity of human mesenchymal stem cells. Biomed Mater Eng. (2017) 28:S29-S45. doi: 10.3233/BME-171622

3. Yin JQ, Zhu J, Ankrum JA. Manufacturing of primed mesenchymal stromal cells for therapy. Nat Biomed Eng. (2019) 3:90-104. doi: 10.1038/s41551-018-0325-8

4. Andrzejewska A, Lukomska B, Janowski M. Concise review: mesenchymal stem cells: from roots to boost. Stem Cells. (2019) 37:855-64. doi: 10.1002/stem.3016

5. Viswanathan S, Shi Y, Galipeau J, Krampera M, Leblanc K, Martin I, et al. Mesenchymal stem versus stromal cells: International Society for Cell \& Gene Therapy (ISCT®) Mesenchymal Stromal Cell committee position statement on nomenclature. Cytotherapy. (2019) 21:1019-24. doi: 10.1016/j.jcyt.2019.08.002

6. Samsonraj RM, Raghunath M, Nurcombe V, Hui JH, van Wijnen AJ, Cool SM. Concise review: multifaceted characterization of human mesenchymal stem cells for use in regenerative medicine. Stem Cells Transl Med. (2017) 6:2173-85. doi: 10.1002/sctm.17-0129

7. Gronthos S, Zannettino ACW, Hay SJ, Shi S, Graves SE, Kortesidis A, et al. Molecular and cellular characterisation of highly purified stromal stem cells derived from human bone marrow. J Cell Sci. (2003) 116:182735. doi: $10.1242 /$ jcs.00369

8. Zuk PA, Zhu M, Ashjian P, De Ugarte DA, Huang JI, Mizuno H, et al. Human adipose tissue is a source of multipotent stem cells. Mol Biol Cell. (2002) 13:4279-95. doi: 10.1091/mbc.e02-02-0105

9. Pittenger MF, Mackay AM, Beck SC, Jaiswal RK, Douglas R, Mosca JD, et al. Multilineage potential of adult human mesenchymal stem cells. Science. (1999) 284:143-7. doi: 10.1126/science.284.5411.143

\section{DATA AVAILABILITY STATEMENT}

The original contributions presented in the study are included in the article/supplementary material, further inquiries can be directed to the corresponding author.

\section{AUTHOR CONTRIBUTIONS}

$\mathrm{RP}$ and $\mathrm{APa}$ : conceptualization. FD and $\mathrm{APi}$ : literature revision and data curation. RP: supervision. APa, OT, and RP: writingoriginal draft preparation and writing-review and editing. All authors have read and agreed to the published version of the manuscript.

\section{FUNDING}

This work was supported by Fondi di Ateneo 2019 from the University G. d'Annunzio to RP.

\section{ACKNOWLEDGMENTS}

The authors thank Dr. Gianluca Carnevale, who helped with the bibliographic search on the subject of this manuscript, and also contributed valuable comments. We are grateful to Prof. Graham Pawelec for the critical reading of the manuscript and for providing very useful suggestions.

10. Selich A, Zimmermann K, Tenspolde M, Dittrich-Breiholz O, von Kaisenberg C, Schambach A, et al. Umbilical cord as a long-term source of activatable mesenchymal stromal cells for immunomodulation. Stem Cell Res Ther. (2019) 10:285. doi: 10.1186/s13287-019-1376-9

11. Williams JT, Southerland SS, Souza J, Calcutt AF, Cartledge RG. Cells isolated from adult human skeletal muscle capable of differentiating into multiple mesodermal phenotypes. Am Surg. (1999) 65:22-6.

12. Patki S, Kadam S, Chandra V, Bhonde R. Human breast milk is a rich source of multipotent mesenchymal stem cells. Hum Cell. (2010) 23:3540. doi: 10.1111/j.1749-0774.2010.00083.x

13. Salingcarnboriboon R, Yoshitake H, Tsuji K, Obinata M, Amagasa T, Nifuji A, et al. Establishment of tendon-derived cell lines exhibiting pluripotent mesenchymal stem cell-like property. Exp Cell Res. (2003) 287:289-300. doi: 10.1016/S0014-4827(03)00107-1

14. In't Anker PS, Scherjon SA, Kleijburg-van der Keur C, de Groot-Swings GMJS, Claas FHJ, Fibbe WE, et al. Isolation of mesenchymal stem cells of fetal or maternal origin from human placenta. Stem Cells. (2004) 22:133845. doi: 10.1634/stemcells.2004-0058

15. De Bari C, Dell'Accio F, Tylzanowski P, Luyten FP. Multipotent mesenchymal stem cells from adult human synovial membrane. Arthritis Rheum. (2001) 44:1928-42. doi: 10.1002/1529-0131(200108)44:8<1928::AID-ART331>3.0. $\mathrm{CO} ; 2-\mathrm{P}$

16. Zhao S, Wehner R, Bornhäuser M, Wassmuth R, Bachmann M, Schmitz M. Immunomodulatory properties of mesenchymal stromal cells and their therapeutic consequences for immune-mediated disorders. Stem Cells Dev. (2010) 19:607-14. doi: 10.1089/scd.2009.0345

17. Zhao Q, Ren H, Han Z. Mesenchymal stem cells: immunomodulatory capability and clinical potential in immune diseases. J Cell Immunother. (2016) 2:3-20. doi: 10.1016/j.jocit.2014.1 2.001

18. Liu J, Yu F, Sun Y, Jiang B, Zhang W, Yang J, et al. Concise reviews: characteristics and potential applications of human dental tissue-derived mesenchymal stem cells. Stem Cells. (2015) 33:62738. doi: 10.1002/stem.1909 
19. Nuti N, Corallo C, Chan BMF, Ferrari M, Gerami-Naini B. Multipotent differentiation of human dental pulp stem cells: a literature review. Stem Cell Rev Rep. (2016) 12:511-23. doi: 10.1007/s12015-016-9661-9

20. Rodríguez-Lozano FJ, Bueno C, Insausti CL, Meseguer L, Ramírez MC, Blanquer M, et al. Mesenchymal stem cells derived from dental tissues: dental stem cells. Int Endodontic J. (2011) 44:800-6. doi: 10.1111/j.1365-2591.2011.01877.x

21. Mayo V, Sawatari Y, Huang C-YC, Garcia-Godoy F. Neural crest-derived dental stem cells-where we are and where we are going. J Dent. (2014) 42:1043-51. doi: 10.1016/j.jdent.2014.04.007

22. Sharpe PT. Dental mesenchymal stem cells. Development. (2016) 143:227380. doi: 10.1242/dev.134189

23. Andrukhov O, Behm C, Blufstein A, Rausch-Fan X. Immunomodulatory properties of dental tissue-derived mesenchymal stem cells: implication in disease and tissue regeneration. WJSC. (2019) 11:604-17. doi: 10.4252/wjsc.v11.i9.604

24. Gronthos S, Mankani M, Brahim J, Robey PG, Shi S. Postnatal human dental pulp stem cells (DPSCs) in vitro and in vivo. Proc Natl Acad Sci USA. (2000) 97:13625-30. doi: 10.1073/pnas.240309797

25. Pierdomenico L, Bonsi L, Calvitti M, Rondelli D, Arpinati M, Chirumbolo $\mathrm{G}$, et al. Multipotent mesenchymal stem cells with immunosuppressive activity can be easily isolated from dental pulp. Transplantation. (2005) 80:836-42. doi: 10.1097/01.tp.0000173794.72151.88

26. Tomic S, Djokic J, Vasilijic S, Vucevic D, Todorovic V, Supic G, et al. Immunomodulatory properties of mesenchymal stem cells derived from dental pulp and dental follicle are susceptible to activation by toll-like receptor agonists. Stem Cells Dev. (2011) 20:695-708. doi: 10.1089/scd.2010.0145

27. Pisciotta A, Bertani G, Bertoni L, Di Tinco R, De Biasi S, Vallarola A, et al. Modulation of cell death and promotion of chondrogenic differentiation by Fas/FasL in human dental pulp stem cells (hDPSCs). Front Cell Dev Biol. (2020) 8:279. doi: 10.3389/fcell.2020.00279

28. Al-Hakami A, Alqhatani SQ, Shaik S, Jalfan SM, Dhammam MSA, Asiri W, et al. Cytokine physiognomies of MSCs from varied sources confirm the regenerative commitment post-coculture with activated neutrophils. J Cell Physiol. (2020) 235:8691-701. doi: 10.1002/jcp.29713

29. Martinez VG, Ontoria-Oviedo I, Ricardo CP, Harding SE, Sacedon R, Varas A, et al. Overexpression of hypoxia-inducible factor 1 alpha improves immunomodulation by dental mesenchymal stem cells. Stem Cell Res Ther. (2017) 8:208. doi: 10.1186/s13287-017-0659-2

30. Pisciotta A, Carnevale G, Meloni S, Riccio M, De Biasi S, Gibellini L, et al. Human dental pulp stem cells (hDPSCs): isolation, enrichment and comparative differentiation of two sub-populations. BMC Dev Biol. (2015) 15:14. doi: 10.1186/s12861-015-0065-x

31. Miura M, Gronthos S, Zhao M, Lu B, Fisher LW, Robey PG, et al. SHED: stem cells from human exfoliated deciduous teeth. Proc Natl Acad Sci USA. (2003) 100:5807-12. doi: 10.1073/pnas.0937635100

32. Yamaza T, Kentaro A, Chen C, Liu Y, Shi Y, Gronthos S, et al. Immunomodulatory properties of stem cells from human exfoliated deciduous teeth. Stem Cell Res Ther. (2010) 1:5. doi: 10.1186/scrt5

33. Kerkis I, Ambrosio CE, Kerkis A, Martins DS, Zucconi E, Fonseca SAS, et al. Early transplantation of human immature dental pulp stem cells from baby teeth to golden retriever muscular dystrophy (GRMD) dogs: local or systemic? J Transl Med. (2008) 6:35. doi: 10.1186/1479-5876-6-35

34. Zhang Z, Huang S, Wu S, Qi J, Li W, Liu S, et al. Clearance of apoptotic cells by mesenchymal stem cells contributes to immunosuppression via PGE2. EBioMedicine. (2019) 45:341-50. doi: 10.1016/j.ebiom.2019.06.016

35. Seo B-M, Miura M, Gronthos S, Bartold PM, Batouli S, Brahim J, et al. Investigation of multipotent postnatal stem cells from human periodontal ligament. Lancet. (2004) 364:149-55. doi: 10.1016/S0140-6736(04)16627-0

36. Trubiani O, Di Primio R, Traini T, Pizzicannella J, Scarano A, Piattelli A, et al. Morphological and cytofluorimetric analysis of adult mesenchymal stem cells expanded ex vivo from periodontal ligament. Int J Immunopathol Pharmacol. (2005) 18:213-21. doi: 10.1177/039463200501800204

37. Trubiani O, Pizzicannella J, Caputi S, Marchisio M, Mazzon E, Paganelli $\mathrm{R}$, et al. Periodontal ligament stem cells: current knowledge and future perspectives. Stem Cells Dev. (2019) 28:995-1003. doi: 10.1089/scd.2019.0025
38. Yagi H, Soto-Gutierrez A, Parekkadan B, Kitagawa Y, Tompkins RG, Kobayashi $\mathrm{N}$, et al. Mesenchymal stem cells: mechanisms of immunomodulation and homing. Cell Transplant. (2010) 19:667-79. doi: 10.3727/096368910X508762

39. Wada N, Menicanin D, Shi S, Bartold PM, Gronthos S. Immunomodulatory properties of human periodontal ligament stem cells. J Cell Physiol. (2009) 219:667-76. doi: 10.1002/jcp.21710

40. Ding G, Liu Y, Wang W, Wei F, Liu D, Fan Z, et al. Allogeneic periodontal ligament stem cell therapy for periodontitis in swine. Stem Cells. (2010) 28:1829-38. doi: 10.1002/stem.512

41. Trubiani O, Giacoppo S, Ballerini P, Diomede F, Piattelli A, Bramanti P, et al. Alternative source of stem cells derived from human periodontal ligament: a new treatment for experimental autoimmune encephalomyelitis. Stem Cell Res Ther. (2016) 7:1. doi: 10.1186/s13287-015-0253-4

42. Rajan TS, Giacoppo S, Diomede F, Ballerini P, Paolantonio M, Marchisio M, et al. The secretome of periodontal ligament stem cells from MS patients protects against EAE. Sci Rep. (2016) 6:38743. doi: 10.1038/srep38743

43. Liu D, Xu J, Liu O, Fan Z, Liu Y, Wang F, et al. Mesenchymal stem cells derived from inflamed periodontal ligaments exhibit impaired immunomodulation. J Clin Periodontol. (2012) 39:1174-82. doi: 10.1111/jcpe.12009

44. Sonoyama W, Liu Y, Yamaza T, Tuan RS, Wang S, Shi S, et al. Characterization of the apical papilla and its residing stem cells from human immature permanent teeth: a pilot study. J Endod. (2008) 34:16671. doi: 10.1016/j.joen.2007.11.021

45. Sonoyama W, Liu Y, Fang D, Yamaza T, Seo B-M, Zhang C, et al. Mesenchymal stem cell-mediated functional tooth regeneration in swine. PLoS ONE. (2006) 1:e79. doi: 10.1371/journal.pone.0000079

46. Ding G, Liu Y, An Y, Zhang C, Shi S, Wang W, et al. Suppression of T cell proliferation by root apical papilla stem cells in vitro. Cells Tissues Organs. (2010) 191:357-64. doi: 10.1159/000276589

47. Ding G, Wang W, Liu Y, An Y, Zhang C, Shi S, et al. Effect of cryopreservation on biological and immunological properties of stem cells from apical papilla. J Cell Physiol. (2010) 223:415-22. doi: 10.1002/jcp.22050

48. Matsubara T, Suardita K, Ishii M, Sugiyama M, Igarashi A, Oda R, et al. Alveolar bone marrow as a cell source for regenerative medicine: differences between alveolar and iliac bone marrow stromal cells. J Bone Miner Res. (2005) 20:399-409. doi: 10.1359/JBMR.041117

49. Cao C, Tarlé S, Kaigler D. Characterization of the immunomodulatory properties of alveolar bone-derived mesenchymal stem cells. Stem Cell Res Ther. (2020) 11:102. doi: 10.1186/s13287-020-01605-x

50. Creanor S, editor. Essential Clinical Oral Biology. Chichester; Ames, IA: Wiley (2016).

51. Morsczeck C, Götz W, Schierholz J, Zeilhofer F, Kühn U, Möhl C, Sippel C, Hoffmann KH. Isolation of precursor cells (PCs) from human dental follicle of wisdom teeth. Matrix Biol. (2005) 24:15565. doi: 10.1016/j.matbio.2004.12.004

52. Chen X, Yang B, Tian J, Hong H, Du Y, Li K, et al. Dental follicle stem cells ameliorate lipopolysaccharide-induced inflammation by secreting TGF- $\beta 3$ and TSP-1 to elicit macrophage M2 polarization. Cell Physiol Biochem. (2018) 51:2290-308. doi: 10.1159/000495873

53. Morsczeck C, Völlner F, Saugspier M, Brandl C, Reichert TE, Driemel O, et al. Comparison of human dental follicle cells (DFCs) and stem cells from human exfoliated deciduous teeth (SHED) after neural differentiation in vitro. Clin Oral Investig. (2010) 14:433-40. doi: 10.1007/s00784-009-0310-4

54. Ikeda E, Yagi K, Kojima M, Yagyuu T, Ohshima A, Sobajima S, et al. Multipotent cells from the human third molar: feasibility of cell-based therapy for liver disease. Differentiation. (2008) 76:495505. doi: 10.1111/j.1432-0436.2007.00245.x

55. Zhang Q, Shi S, Liu Y, Uyanne J, Shi Y, Shi S, et al. Mesenchymal stem cells derived from human gingiva are capable of immunomodulatory functions and ameliorate inflammation-related tissue destruction in experimental colitis. J Immunol. (2009) 183:7787-98. doi: 10.4049/jimmunol.0902318

56. Su W-R, Zhang Q-Z, Shi S-H, Nguyen AL, Le AD. Human gingivaderived mesenchymal stromal cells attenuate contact hypersensitivity via prostaglandin E2-dependent mechanisms. Stem Cells. (2011) 29:184960. doi: $10.1002 /$ stem.738 
57. Chen M, Su W, Lin X, Guo Z, Wang J, Zhang Q, et al. Adoptive transfer of human gingiva-derived mesenchymal stem cells ameliorates collageninduced arthritis via suppression of Th1 and Th17 cells and enhancement of regulatory T cell differentiation. Arthritis Rheum. (2013) 65:118193. doi: 10.1002/art.37894

58. Zhang Q-Z, Su W-R, Shi S-H, Wilder-Smith P, Xiang AP, Wong A, et al. Human gingiva-derived mesenchymal stem cells elicit polarization of $\mathrm{m} 2$ macrophages and enhance cutaneous wound healing. Stem Cells. (2010) 28:1856-68. doi: 10.1002/stem.503

59. De Miguel MP, Fuentes-Julián S, Blázquez-Martínez A, Pascual CY, Aller MA, Arias J, et al. Immunosuppressive properties of mesenchymal stem cells: advances and applications. Curr Mol Med. (2012) 12:57491. doi: 10.2174/156652412800619950

60. Jiang X-X, Zhang Y, Liu B, Zhang S-X, Wu Y, Yu X-D, et al. Human mesenchymal stem cells inhibit differentiation and function of monocyte-derived dendritic cells. Blood. (2005) 105:4120-6. doi: 10.1182/blood-2004-02-0586

61. Chen L, Zhang W, Yue H, Han Q, Chen B, Shi M, et al. Effects of human mesenchymal stem cells on the differentiation of dendritic cells from CD34+ cells. Stem Cells Dev. (2007) 16:719-31. doi: 10.1089/scd.2007.0065

62. Spaggiari GM, Abdelrazik H, Becchetti F, Moretta L. MSCs inhibit monocytederived DC maturation and function by selectively interfering with the generation of immature DCs: central role of MSCs-derived prostaglandin E2. Blood. (2009) 113:6576-83. doi: 10.1182/blood-2009-02-203943

63. Djouad F, Charbonnier L-M, Bouffi C, Louis-Plence P, Bony C, Apparailly F, et al. Mesenchymal stem cells inhibit the differentiation of dendritic cells through an interleukin-6-dependent mechanism. Stem Cells. (2007) 25:2025-32. doi: 10.1634/stemcells.2006-0548

64. Spaggiari GM, Capobianco A, Becchetti S, Mingari MC, Moretta L. Mesenchymal stem cell-natural killer cell interactions: evidence that activated NK cells are capable of killing MSCs, whereas MSCs can inhibit IL-2-induced NK-cell proliferation. Blood. (2006) 107:148490. doi: 10.1182/blood-2005-07-2775

65. Spaggiari GM, Capobianco A, Abdelrazik H, Becchetti F, Mingari MC, Moretta L. Mesenchymal stem cells inhibit natural killercell proliferation, cytotoxicity, and cytokine production: role of indoleamine 2,3-dioxygenase and prostaglandin E2. Blood. (2008) 111:1327-33. doi: 10.1182/blood-2007-02-074997

66. Augello A, Tasso R, Negrini SM, Amateis A, Indiveri F, Cancedda R, et al. Bone marrow mesenchymal progenitor cells inhibit lymphocyte proliferation by activation of the programmed death 1 pathway. Eur J Immunol. (2005) 35:1482-90. doi: 10.1002/eji.200425405

67. Comoli P, Ginevri F, Maccario R, Avanzini MA, Marconi M, Groff A, et al. Human mesenchymal stem cells inhibit antibody production induced in vitro by allostimulation. Nephrol Dial Transplant. (2008) 23:1196202. doi: $10.1093 / \mathrm{ndt} / \mathrm{gfm} 740$

68. Che N, Li X, Zhang L, Liu R, Chen H, Gao X, et al. Impaired B cell inhibition by lupus bone marrow mesenchymal stem cells is caused by reduced CCL2 expression. JI. (2014) 193:5306-14. doi: 10.4049/jimmunol.1400036

69. Casiraghi F, Azzollini N, Cassis P, Imberti B, Morigi M, Cugini D, et al. Pretransplant infusion of mesenchymal stem cells prolongs the survival of a semiallogeneic heart transplant through the generation of regulatory $\mathrm{T}$ cells. J Immunol. (2008) 181:3933-46. doi: 10.4049/jimmunol.181.6.3933

70. Maccario R, Podestà M, Moretta A, Cometa A, Comoli P, Montagna D, et al. Interaction of human mesenchymal stem cells with alloantigeninduced $\mathrm{T}$ lymphocyte activation favors the differentiation of CD4+ T cell subsets expressing CD25 and/or CTLA4 molecules. Blood. (2004) 104:2123. doi: 10.1182/blood.V104.11.2123.2123

71. English K, Ryan JM, Tobin L, Murphy MJ, Barry FP, Mahon BP. Cell contact, prostaglandin $\mathrm{E}(2)$ and transforming growth factor beta 1 play non-redundant roles in human mesenchymal stem cell induction of CD4+CD25(High) forkhead box P3+ regulatory T cells. Clin Exp Immunol. (2009) 156:149-60. doi: 10.1111/j.1365-2249.2009.03874.X

72. Kunimatsu R, Nakajima K, Awada T, Tsuka Y, Abe T, Ando K, et al. Comparative characterization of stem cells from human exfoliated deciduous teeth, dental pulp, and bone marrow-derived mesenchymal stem cells. Biochem Biophys Res Commun. (2018) 501:193-8. doi: 10.1016/j.bbrc.2018.04.213
73. Li J, Xu S-Q, Zhao Y-M, Yu S, Ge L-H, Xu B-H. Comparison of the biological characteristics of human mesenchymal stem cells derived from exfoliated deciduous teeth, bone marrow, gingival tissue, and umbilical cord. Mol Med Rep. (2018) 18:4969-77. doi: 10.3892/mmr.2018.9501

74. Paganelli A, Tarentini E, Benassi L, Kaleci S, Magnoni C. Mesenchymal stem cells for the treatment of psoriasis: a comprehensive review. Clin Exp Dermatol. (2020) 45:824-830. doi: 10.1111/ced.14269

75. Shin T-H, Kim H-S, Choi S, Kang K-S. Mesenchymal stem cell therapy for inflammatory skin diseases: clinical potential and mode of action. Int J Mol Sci. (2017) 18:244. doi: 10.3390/ijms18020244

76. Meng Q-S, Liu J, Wei L, Fan H-M, Zhou X-H, Liang X-T. Senescent mesenchymal stem/stromal cells and restoring their cellular functions. World J Stem Cells. (2020) 12:966-85. doi: 10.4252/wjsc.v12.i9.966

77. Wang M, Yuan Q, Xie L. Mesenchymal stem cell-based immunomodulation: properties and clinical application. Stem Cells Int. (2018) 2018:112. doi: $10.1155 / 2018 / 3057624$

78. Chen Y, Yu Q, Hu Y, Shi Y. Current research and use of mesenchymal stem cells in the therapy of autoimmune diseases. Curr Stem Cell Res Ther. (2019) 14:579-82. doi: 10.2174/1574888X14666190429141421

79. Dave JR, Tomar GB. Dental tissue-derived mesenchymal stem cells: applications in tissue engineering. Crit Rev Biomed Eng. (2018) 46:42968. doi: 10.1615/CritRevBiomedEng.2018027342

80. Estrela C, Alencar AHG de, Kitten GT, Vencio EF, Gava E. Mesenchymal stem cells in the dental tissues: perspectives for tissue regeneration. Braz Dent J. (2011) 22:91-8. doi: 10.1590/S0103-64402011000200001

81. Qi K, Li N, Zhang Z, Melino G. Tissue regeneration: the crosstalk between mesenchymal stem cells and immune response. Cell Immunol. (2018) 326:86-93. doi: 10.1016/j.cellimm.2017.11.010

82. Oltz EM, Schwab S. Stromal immunology: frameworks for development and response. J Immunol. (2021) 206:241-2. doi: 10.4049/jimmunol.2090022

83. Nayar S, Campos J, Smith CG, Iannizzotto V, Gardner DH, Mourcin F, et al. Immunofibroblasts are pivotal drivers of tertiary lymphoid structure formation and local pathology. Proc Natl Acad Sci USA. (2019) 116:134907. doi: 10.1073/pnas. 1905301116

84. Barone F, Gardner DH, Nayar S, Steinthal N, Buckley CD, Luther SA. Stromal fibroblasts in tertiary lymphoid structures: a novel target in chronic inflammation. Front Immunol. (2016) 7:477. doi: 10.3389/fimmu.2016.00477

85. Gago da Graça C, van Baarsen LGM, Mebius RE. Tertiary lymphoid structures: diversity in their development, composition, and role. J Immunol. (2021) 206:273-81. doi: 10.4049/jimmunol.2000873

86. Chen L, Oke T, Siegel N, Cojocaru G, Tam AJ, Blosser RL, et al. The immunosuppressive niche of soft-tissue sarcomas is sustained by tumor-associated macrophages and characterized by intratumoral tertiary lymphoid structures. Clin Cancer Res. (2020) 26:4018-30. doi: 10.1158/1078-0432.CCR-19-3416

87. Yamada Y, Nakamura-Yamada S, Kusano K, Baba S. Clinical potential and current progress of dental pulp stem cells for various systemic diseases in regenerative medicine: a concise review. IJMS. (2019) 20:1132. doi: 10.3390/ijms20051132

88. Stanko P, Altanerova U, Jakubechova J, Repiska V, Altaner C. Dental mesenchymal stem/stromal cells and their exosomes. Stem Cells Int. (2018) 2018:1-8. doi: 10.1155/2018/8973613

89. Rajan TS, Giacoppo S, Trubiani O, Diomede F, Piattelli A, Bramanti $P$, et al. Conditioned medium of periodontal ligament mesenchymal stem cells exert anti-inflammatory effects in lipopolysaccharide-activated mouse motoneurons. Exp Cell Res. (2016) 349:152-61. doi: 10.1016/j.yexcr.2016.10.008

90. Guo M, Yin Z, Chen F, Lei P. Mesenchymal stem cell-derived exosome: a promising alternative in the therapy of Alzheimer's disease. Alzheimers Res Ther. (2020) 12:109. doi: 10.1186/s13195-020-00670-x

91. Börger V, Bremer M, Ferrer-Tur R, Gockeln L, Stambouli O, Becic A, et al. Mesenchymal stem/stromal cell-derived extracellular vesicles and their potential as novel immunomodulatory therapeutic agents. Int J Mol Sci. (2017) 18:1450. doi: 10.3390/ijms18071450

92. Le Blanc K, Davies LC. MSCs-cells with many sides. Cytotherapy. (2018) 20:273-8. doi: 10.1016/j.jcyt.2018.01.009

93. Ballerini P, Diomede F, Petragnani N, Cicchitti S, Merciaro I, Cavalcanti $\mathrm{MFXB}$, et al. Conditioned medium from relapsing-remitting multiple 
sclerosis patients reduces the expression and release of inflammatory cytokines induced by LPS-gingivalis in THP-1 and MO3.13 cell lines. Cytokine. (2017) 96:261-72. doi: 10.1016/j.cyto.2017.04.022

94. Wang M, Xie J, Wang C, Zhong D, Xie L, Fang H. Immunomodulatory properties of stem cells in periodontitis: current status and future prospective. Stem Cells Int. (2020) 2020:9836518. doi: 10.1155/2020/9836518

95. Raffaghello L, Lee C, Safdie FM, Wei M, Madia F, Bianchi G, et al. Starvationdependent differential stress resistance protects normal but not cancer cells against high-dose chemotherapy. Proc Natl Acad Sci USA. (2008) 105:821520. doi: 10.1073/pnas.0708100105

96. Zhou J, Nefedova Y, Lei A, Gabrilovich D. Neutrophils and PMN-MDSC: their biological role and interaction with stromal cells. Semin Immunol. (2018) 35:19-28. doi: 10.1016/j.smim.2017.12.004

97. Ren W, Hou J, Yang C, Wang H, Wu S, Wu Y, et al. Extracellular vesicles secreted by hypoxia pre-challenged mesenchymal stem cells promote nonsmall cell lung cancer cell growth and mobility as well as macrophage M2 polarization via miR-21-5p delivery. J Exp Clin Cancer Res. (2019) 38:62. doi: 10.1186/s13046-019-1027-0

98. Liu F, Qiu H, Xue M, Zhang S, Zhang X, Xu J, et al. MSCssecreted TGF- $\beta$ regulates lipopolysaccharide-stimulated macrophage M2like polarization via the Akt/FoxO1 pathway. Stem Cell Res Ther. (2019) 10:345. doi: 10.1186/s13287-019-1447-y

99. Pajarinen J, Lin T, Gibon E, Kohno Y, Maruyama M, Nathan K, et al. Mesenchymal stem cell-macrophage crosstalk and bone healing. Biomaterials. (2019) 196:80-9. doi: 10.1016/j.biomaterials.2017.12.025

100. Wu X, Jiang J, Gu Z, Zhang J, Chen Y, Liu X. Mesenchymal stromal cell therapies: immunomodulatory properties and clinical progress. Stem Cell Res Ther. (2020) 11:345. doi: 10.1186/s13287-020-01855-9

101. Jimenez-Puerta GJ, Marchal JA, López-Ruiz E, Gálvez-Martín P. Role of mesenchymal stromal cells as therapeutic agents: potential mechanisms of action and implications in their clinical use. J Clin Med. (2020) 9:445. doi: $10.3390 /$ jcm 9020445

102. Guerrouahen BS, Sidahmed H, Al Sulaiti A, Al Khulaifi M, Cugno C. Enhancing mesenchymal stromal cell immunomodulation for treating conditions influenced by the immune system. Stem Cells Int. (2019) 2019:7219297. doi: 10.1155/2019/7219297

103. Chen X, Wang S, Cao W. Mesenchymal stem cell-mediated immunomodulation in cell therapy of neurodegenerative diseases. Cell Immunol. (2018) 326:8-14. doi: 10.1016/j.cellimm.2017.06.006

104. Abbasi-Kangevari M, Ghamari S-H, Safaeinejad F, Bahrami S, Niknejad H. Potential therapeutic features of human amniotic mesenchymal stem cells in multiple sclerosis: immunomodulation, inflammation suppression, angiogenesis promotion, oxidative stress inhibition, neurogenesis induction, MMPs regulation, and remyelination stimulation. Front Immunol. (2019) 10:238. doi: 10.3389/fimmu.2019.0 0238

105. Baharlooi H, Azimi M, Salehi Z, Izad M. Mesenchymal stem cellderived exosomes: a promising therapeutic ace card to address autoimmune diseases. IJSC. (2020) 13:13-23. doi: 10.15283/ijsc1 9108

106. Cruz-Barrera M, Flórez-Zapata N, Lemus-Diaz N, Medina C, Galindo C-C, González-Acero L-X, et al. Integrated analysis of transcriptome and secretome from umbilical cord mesenchymal stromal cells reveal new mechanisms for the modulation of inflammation and immune activation. Front Immunol. (2020) 11:575488. doi: 10.3389/fimmu.2020.57 5488

107. Sigmarsdóttir $\mathrm{P}^{*}$, McGarrity S, Rolfsson Ó, Yurkovich JT, Sigurjónsson ÓE. Current status and future prospects of genome-scale metabolic modeling to optimize the use of mesenchymal stem cells in regenerative medicine. Front Bioeng Biotechnol. (2020) 8:239. doi: 10.3389/fbioe.2020.0 0239

108. Zumla A, Wang F-S, Ippolito G, Petrosillo N, Agrati C, Azhar EI, et al. Reducing mortality and morbidity in patients with severe COVID-19 disease by advancing ongoing trials of Mesenchymal Stromal (stem) Cell (MSCs) therapy - achieving global consensus and visibility for cellular hostdirected therapies. Int J Infect Dis. (2020) 96:431-9. doi: 10.1016/j.ijid.2020.0 5.040
109. Gupta A, Kashte S, Gupta M, Rodriguez HC, Gautam SS, Kadam S. Mesenchymal stem cells and exosome therapy for COVID19: current status and future perspective. Hum Cell. (2020) 33:907-18. doi: 10.1007/s13577-020-00407-w

110. Basiri A, Mansouri F, Azari A, Ranjbarvan P, Zarein F, Heidari A, et al. Stem cell therapy potency in personalizing severe COVID-19 treatment. Stem Cell Rev Rep. (2021) 17:193-213. doi: 10.1007/s12015-020-10110-w

111. Sengupta V, Sengupta S, Lazo A, Woods P, Nolan A, Bremer N. Exosomes derived from bone marrow mesenchymal stem cells as treatment for severe COVID-19. Stem Cells Dev. (2020) 29:747-54. doi: 10.1089/scd.2020. 0080

112. Coelho A, Alvites RD, Branquinho MV, Guerreiro SG, Maurício AC. Mesenchymal stem cells (MSCs) as a potential therapeutic strategy in COVID-19 patients: literature research. Front Cell Dev Biol. (2020) 8:602647. doi: 10.3389/fcell.2020.60 2647

113. Li W, Chen W, Huang S, Yao G, Tang X, Sun L. Mesenchymal stem cells prevent overwhelming inflammation and reduce infection severity via recruiting CXCR3+ regulatory $\mathrm{T}$ cells. Clin Transl Immunol. (2020) 9:e1181. doi: 10.1002/cti2. 1181

114. Juárez-Navarro KJ, Padilla-Camberos E, Díaz NF, MirandaAltamirano A, Díaz-Martínez NE. Human mesenchymal stem cells: the present alternative for high-incidence diseases, even SARSCov-2. Stem Cells Int. (2020) 2020:1-13. doi: 10.1155/2020/889 2189

115. Antonioli E, Torres N, Ferretti M, Piccinato C de A, Sertie AL. Individual response to mTOR inhibition in delaying replicative senescence of mesenchymal stromal cells. PLoS ONE. (2019) 14:e0204784. doi: 10.1371/journal.pone.0204 784

116. Gnani D, Crippa S, Della Volpe L, Rossella V, Conti A, Lettera $\mathrm{E}$, et al. An early-senescence state in aged mesenchymal stromal cells contributes to hematopoietic stem and progenitor cell clonogenic impairment through the activation of a pro-inflammatory program. Aging Cell. (2019) 18:e12933. doi: 10.1111/acel.1 2933

117. Yu J, Shi J, Zhang Y, Zhang Y, Huang Y, Chen Z, et al. The replicative senescent mesenchymal stem / stromal cells defect in DNA damage response and anti-oxidative capacity. Int J Med Sci. (2018) 15:77181. doi: $10.7150 /$ ijms. 24635

118. Yin Y, Wu R-X, He X-T, Xu X-Y, Wang J, Chen F-M. Influences of age-related changes in mesenchymal stem cells on macrophages during in-vitro culture. Stem Cell Res Ther. (2017) 8:153. doi: 10.1186/s13287-017-0608-0

119. Lee S, Yu K-R, Ryu Y-S, Oh YS, Hong I-S, Kim H-S, et al. miR-543 and miR590-3p regulate human mesenchymal stem cell aging via direct targeting of AIMP3/p18. Age. (2014) 36:9724. doi: 10.1007/s11357-014-9724-2

120. Mohd Ali N, Boo L, Yeap SK, Ky H, Satharasinghe DA, Liew WC, et al. Probable impact of age and hypoxia on proliferation and microRNA expression profile of bone marrow-derived human mesenchymal stem cells. PeerJ. (2016) 4:e1536. doi: 10.7717/peerj.1536

121. Liu X, Yin M, Liu X, Da J, Zhang K, Zhang X, et al. Analysis of hub genes involved in distinction between aged and fetal bone marrow mesenchymal stem cells by robust rank aggregation and multiple functional annotation methods. Front Genet. (2020) 11:573877. doi: 10.3389/fgene.2020.57 3877

122. Kim N, Im K-I, Lim J-Y, Jeon E-J, Nam Y-S, Kim E-J, et al. Mesenchymal stem cells for the treatment and prevention of graft-versushost disease: experiments and practice. Ann Hematol. (2013) 92:1295308. doi: 10.1007/s00277-013-1796-z

123. Zhou T, Li H-Y, Liao C, Lin W, Lin S. Clinical efficacy and safety of mesenchymal stem cells for systemic lupus erythematosus. Stem Cells Int. (2020) 2020:1-11. doi: 10.1155/2020/651 8508

124. Zhang S, Yang Y, Fan L, Zhang F, Li L. The clinical application of mesenchymal stem cells in liver disease: the current situation and potential future. Ann Transl Med. (2020) 8:565-5. doi: 10.21037/atm.2020.03.218 
125. Ko JZ-H, Johnson S, Dave M. Efficacy and safety of mesenchymal stem/stromal cell therapy for inflammatory bowel diseases: an up-to-date systematic review. Biomolecules. (2021) 11:82. doi: 10.3390/biom11010082

Conflict of Interest: The authors declare that the research was conducted in the absence of any commercial or financial relationships that could be construed as a potential conflict of interest.
Copyright (c) 2021 Paganelli, Trubiani, Diomede, Pisciotta and Paganelli. This is an open-access article distributed under the terms of the Creative Commons Attribution License (CC BY). The use, distribution or reproduction in other forums is permitted, provided the original author(s) and the copyright owner $(s)$ are credited and that the original publication in this journal is cited, in accordance with accepted academic practice. No use, distribution or reproduction is permitted which does not comply with these terms. 